\title{
As Populações De Rua Nas Grandes Metrópoles: Reflexões Sobre Tensões, Conflitos E Territorialidades Nos Espaços Públicos
}

\author{
Igor Martins Medeiros Robaina ${ }^{1}$
}

\section{Resumo}

As configurações socioespaciais dos espaços públicos se ressignificam profundamente nas grandes metrópoles. Deste modo, no presente trabalho caminhamos no sentido de compreender as apropriações e territorializações/territorialidades dos grupos marginalizados nestes espaços, especificamente das populações de rua nas grandes metrópoles. Buscamos assim, elucidar os inúmeros processos de ressignificação privada que se desenvolvem nos espaços públicos entre os inúmeros grupos marginalizados na difícil busca pela sobrevivência. As populações de rua, dentre a mais estigmatizada e sofrida, possuem nos espaços públicos as últimas possibilidades de manterem sua sobrevivência, mas ao mesmo tempo estarão diante de inúmeras tensões, conflitos e processos de des(re)territorializações nos espaços públicos, como estratégias de resistência e sobrevivência sócioterritorial.

Palavras-Chaves: Território, Espaços públicos, Grupos Marginalizados e Populações de Rua.

\begin{abstract}
The socio-spatial configurations of public spaces resignifying deeply in large metropolis. Thus, this study walked on understanding the appropriation and territorialization/territoriality of marginalized groups in these spaces specifically the homeless in large metropolis. We sought, therefore, to elucidate the various processes that develop in resignification private in public spaces among marginalized groups in the difficult struggle for survival. The homeless populations, amongst the most stigmatized and suffered in public spaces have the last chances to maintain their survival, but at the same time they will be faced with many tensions, conflicts and processes of re-territorialization in public spaces, with as strategies of resistance and survival space.
\end{abstract}

Key Words: Territory, Public spaces, Marginalized Groups and homeless. 
O morador de rua adapta seu corpo a essa geografia compressora; vai se reconfigurando na medida em que o espaço o limita e molda de forma contingente 0 extravasamento de suas emoções - raiva, angústia, euforia, medo, solidão, dor, alegria - na própria mobilidade. Essa corporalidade pode ser traduzida ora na imobilidade e na retenção de movimentos, a evitar conflito com transeuntes e caber nos lugares mínimos para os quais são expulsos, ora ao externar explosivamente seus gestos, sua fala, sua agressividade, seus desejos. (FRANGELLA, 2005, p. 204)

\section{Introdução}

As grandes metrópoles como importantes realidades socioespaciais se caracterizam de maneira extremamente complexa, seja em relação aos sujeitos, as redes sociais vividas cotidianamente Seus espaços são um resultado das produções acumulativas ao longo dos tempos e suas dinâmicas estão organizadas a partir das contínuas interelações de poderes entre os diferentes grupos sociais e seus respectivos interesses.

De tal modo, que a coexistência destes grupos nas grandes metrópoles, assim como suas relações e dimensões espaciais que se interagem em determinados momentos, sejam de maneira pacífica, quanto conflituosa produzem arranjos e realidades sócio-espaciais únicas frente a complexidade que é o urbano metropolitano.

A ação de transitar pelas ruas das grandes metrópoles é certamente fascinante. Inúmeras são as cores, formas e movimentos que materializam novas paisagens a cada esquina, logicamente, se percebidos a partir de uma ótica atenta e sensível a este conjunto complexo existente. Contudo, pese a toda beleza e riqueza presente no urbano, nem tudo é encanto. A circulação por estas mesmas ruas nos revela as contradições de um urbano que, muitas vezes esquecido, é tão doloroso para aqueles que nele vivem, principalmente quando consideramos os "sentidos de justiça, de equidade, solidariedade, ética ou direitos civis"(GOMES, 2006:129).

Esta complexidade da metrópole contemporânea, principalmente como um reflexo de uma estrutura capitalista nas grandes metrópoles, haverá uma série de contradições e desigualdades extremamente marcantes. Assim, mesmo reconhecendo que nas grandes metrópoles está concentrada a maior parte das riquezas produzidas espacialmente pelos homens, pode-se questionar se o oposto também não se materializa com a mesma magnitude. Esta realidade - oposta à fruição das possibilidades advindas da produção de riqueza - pode ser contemplada a partir das múltiplas formas de precariedade, vulnerabilidade e miserabilidade que estão presentes e são vivenciadas cotidianamente por muitos sujeitos no espaço urbano. Torna-se assim, impossível em qualquer mínima medida, dissociar tais desigualdades da própria condição do urbano. Por outras palavras, na configuração dos espaços urbanos, milhões de indivíduos, em todo o mundo, estão sendo levados à condição de lhes ser negado, paradoxalmente, o direito à cidade ${ }^{2}$ : não fazem 
parte plenamente da Urbs, seja em relação ao acesso aos serviços, seja nas condições de trabalho (ou da inexistência da oferta deste), seja no (não) atendimento ao direito de possuírem um lar - essa necessidade sócioespacial que serve de base para o exercício de tantos outros direitos.

\section{Os Espaços Públicos e Suas Transformações Sócio-Histórico-Espaciais}

Diante destas contradições, caminhamos no sentido de compreender os espaços públicos das grandes metrópoles, assim como as suas relações com os grupos marginalizados socioespacialmente, especificamente o caso das populações de rua.

Alguns autores dedicaram-se em analisar questões relacionadas aos espaços públicos nas grandes metrópoles ${ }^{3}$, como um importante instrumento de compreensão da própria sociedade, assim como a possibilidade de emersão de uma nova categoria analítico-geográfica.

Sobre esta questão, reflete Gomes:

Um olhar geográfico sobre o espaço público deve considerar, por um lado, sua configuração física e, por outro, o tipo de práticas e dinâmicas sociais que aí se desenvolvem. Ela passa então a ser vista como um conjunto indissociável das formas com as práticas sociais. É justamente sob este ângulo que a noção de espaço público pode vir a se constituir em uma categoria de análise geográfica.(GOMES, p.172, 2006)

Muitas são as concepções que se tem dos espaços públicos, visto que muitas são as análises e os focos, em objetos diferenciados e por inúmeros campos do conhecimento científico (Antropologia, Artes, Arquitetura e Urbanismo, Ciência política, Geografia, História, Sociologia, entre outras) sobre/no espaço público. Contudo, uma grande preocupação ao pensarmos analiticamente nestes espaços, deve estar em não acatarmos de maneira simplista, a compreensão dos espaços públicos meramente como uma oposição a tudo que não esteja relacionado com espaços privados ou vice versa.

Assim, nos aproximamos de alguns autores e suas respectivas obras que nos dão base para reflexões e desencadeamentos futuros sobre os espaços urbanos nas grandes metrópoles.

Iniciamos esta abordagem com uma importante referência sobre a análise social, a partir das dimensões do espaço público desenvolvida por Richard Sennett, em sua obra O declínio do homem público: as tiranias da intimidade. Segundo este autor, originalmente os espaços públicos se constituíam como um verdadeiro lócus da democracia, servindo como verdadeiros espaços de tolerância às alteridades, e principalmente como um espaço para o diálogo da própria coletividade na tentativa de solucionar os seus problemas.

Ao longo do tempo, Sennett demonstrou em sua obra que estes mesmos espaços públicos foram sendo resignificados substancialmente e se tornando meramente uma instância formal, onde se antes eram espaços de 


\section{REVISTA TAMOIOS}

permanência, ou seja, de vivência, passaram a ser meramente vias de circulação. Este fato, Sennett denominou de Erosão da vida pública ${ }^{4}$

Algumas são as possíveis explicações em torno destas modificações que alteraram o comportamento dos sujeitos em relação aos espaços públicos e principalmente na transformação destes na própria configuração espacial do urbano. Contudo, segundo Sennett, a principal causa foi proporcionada pelas transformações do capitalismo e suas alterações psicológicas e sociais, nas quais inverteram e corroeram as preocupações anteriormente ligadas aos espaços e assuntos públicos em detrimento aos privados.

Segundo Sennett:

Multidões de pessoas estão agora preocupadas, mais do que nunca, apenas com as histórias de suas próprias vidas e com suas emoções particulares; esta preocupação tem demonstrado ser mais uma armadilha do que uma libertação. (SENNETT, p. 17, 1988)

Geograficamente, caminhamos principalmente a partir das luzes de Paulo César Gomes para a compreensão dos espaços públicos. Este autor se enquadra numa visão contestatória do que deveriam ser estes espaços e o que realmente eles são ou representam atualmente nas/para as grandes metrópoles.

Desta forma, Gomes possui uma interpretação do espaço público bastante ampla e orientada pelos referenciais espaciais geográficos que caracterizam principalmente as relações e práticas sociais diante os espaços produzidos.

Segundo Gomes:

O espaço público é, antes de mais nada, o lugar, praça, rua, shopping, praia, qualquer tipo de espaço, onde não haja obstáculos à possibilidades de acesso e participação de qualquer tipo de pessoa (...) Essa acessibilidade é física, mas também diz respeito ao fato de que não deve estar condicionada à força de quaisquer outros critérios senão daqueles impostos pela lei que regula os comportamentos em áreas comuns. (GOMES, p.162, 2006)

Assim, Gomes, seguindo uma visão de Sennett, também acredita num importante papel dos espaços públicos nas metrópoles de um modo geral, pois seriam "simultaneamente o lugar onde os problemas se apresentam, tomam forma, ganham uma dimensão pública e, simultaneamente, são resolvidos" 5 . Ou pelo menos deveriam ser.

Entretanto, este mesmo espaço público compreendido concomitantemente como lócus da democracia e liberdade para a circulação/acessibilidades do cidadão se destorce de suas funções originais e passam a atender outros fins e interesses específicos, principalmente capitalistas. Assim, o antigo papel da "dimensão do homem público se estreita, restringindo-se à de um mero passante ou no máximo se limitando à de um eventual consumidor" 6 . Assim, os espaços públicos se esvaziam das suas 


\section{REVISTA TAMOIOS}

funções originais ou são reapropriados de maneira diferenciada ao modelo pensado originalmente.

Por fim, um modo bastante peculiar para a compreensão do espaço público é composto pelo antropólogo Roberto da Matta, em sua obra: A Casa e a Rua: Espaço, Cidadania, Mulher e Morte no Brasil. Sua principal preocupação caminha na busca de uma compreensão sócio-antropológica da sociedade brasileira, mas estendendo-se também aos casos ibéricos e católicos, a partir de uma dimensão articulada entre a casa e a rua.

Segundo Da Matta, estas duas categorias estariam diretamente ligadas as dimensões espaciais do público (Rua) e do privado (Casa). Contudo, o autor caminha também num sentido negativo, principalmente relacionado ao espaço público em detrimento ao espaço privado, como praticamente uma condicionante inexorável e escolhida conscientemente pela própria sociedade e seu conjunto de ações.

Segundo Da Matta:

Em casa somos todos, conforme tenho dito, "supercidadãos". Mas e na rua? Bem, aqui passamos sempre por indivíduos anônimos e desgarrados, somos quase sempre maltratados pelas chamadas "autoridades" e não temos paz, nem voz. Somos rigorosamente "subcidadãos" e não será exagerado observar que, por causa disso, nosso comportamento na rua (e nas coisas públicas que ela necessariamente encerra) é igualmente negativo. Jogamos o lixo para fora da nossa calçada, portas e janelas; não obedecemos às regras de trânsito, somos até mesmo capazes de depredar a coisa comum, utilizando aquele célebre e não analisado argumento segundo o qual tudo que fica fora de nossa casa é um "problema do governo"! (MATTA, p.20, 1997)

Deste modo, o espaço público se tornou a partir das representações e práticas sociais, como algo extremamente negativo, ou seja, "destinado à passagem, não a permanência"7, onde as ruas, como expressão máxima desta dimensão, configuram-se como espaços que são extremamente imprevisíveis e perigosos, tendo em comparação associativa a proteção do lar como espaço restrito e destinado a um pequeno grupo familiar.

Portanto, caminhamos no sentido de compreender como determinados sujeitos, por conta de uma série de acontecimentos estruturais que fogem aos seus desejos e controles são levados as ruas e, fazendo com que estas se tornem um espaço permanente e vivido. Esta materialidade das populações de rua nos espaços públicos, de certo modo, torna-se uma ruptura com a ordem estabelecida, não por opção, mas por impossibilidade de qualquer outra forma de sobrevivência, geradora de conflitos e contraditória se pensarmos os espaços públicos como o lócus da própria democracia. 


\section{As Territorializações e Territorialidades Nos Espaços Públicos: 0 Caso Das Populações De Rua}

Nas grandes metrópoles, inúmeros são os grupos que usufruem dos espaços públicos. Assim como é importante destacarmos que, diferentes são as formas de apropriações espaço-temporais que estes grupos se materializam e se justapõem concomitantemente nestes espaços, mesmo que isto ocorra de maneira diferenciada e em múltiplos níveis escalas e especificidades funcionais.

Neste conjunto complexo em questão, se inserem também os grupos marginalizados, dentre eles, as populações de rua. As dificuldades econômicas e a impossibilidade de outros espaços próprios (privados) para a reprodução da vida social e econômica faz com que inúmeros sujeitos passem a ser obrigados a utilizar as ruas, ou seja, os espaços públicos como meio de sobrevivência. Alguns de forma permanente e outros configurados a uma dinâmica mais temporária.

Neste sentido, as relações destes sujeitos e de suas vidas com os espaços públicos se tornam de tal modo arraigado que, analisá-los de maneira dissociada das dimensões espaciais nos faz perder uma série de elementos da própria realidade e sua complexidade em questão.

Deste modo, o conceito de território funciona como um importante instrumento científico-analítico para direcionarmos inúmeras reflexões sobre a realidade, e principalmente por este se configurar "como uma das chaves de acesso à interpretação de práticas sociais circunscrita a uma dada porção do espaço".

De fato, quando pensamos no conceito de território, caminhamos principalmente na impossibilidade existencial de indivíduo ou grupo social que não possua uma relação espacial e consequentemente territorial ${ }^{9}$ mesmo que estas formas de territoriailização e/ou suas territorialidades se materializem de maneira precária, temporária ou simbólica, mas todas possuindo em sua base, estratégias de apropriações, controles ou simplesmente usos de uma parcela espacial com um intuito vital para o desenvolvimento de suas vidas.

Sobre este respeito, descreve Haesbaert:

Essa "necessidade territorial" ou de controle e apropriação do espaço pode estender-se desde um nível mais físico ou biológico (enquanto seres com necessidades básicas como água, ar, alimento, abrigo para repousar), até um nível mais imaterial ou simbólico (enquanto seres dotados do poder da representação e da imaginação e que a todo instante re-significam e se apropriam simbolicamente do seu meio) (...). (HAESBAERT, R. 2004, p.340).

A partir destas relações entre os sujeitos e suas estratégias territoriais, que acreditamos na interelação dos grupos marginalizados nos espaços públicos. De fato, os espaços públicos pensados na presente configuração socioespacial, obviamente não são aqueles idealizados para os fins da coletividade e na resolução de seus respectivos problemas, mas sim, como 


\section{REVISTA TAMOIOS}

possibilidade de sobrevivência em meio às adversidades nos grandes centros urbanos por determinados sujeitos ou grupos sociais.

Deste modo, os espaços públicos podem ser representados comparativamente como um verdadeiro caleidoscópio, onde a cada novo movimento-momento, a cada peça com suas respectivas cores e formas, representem os sujeitos e/ou grupos. Contudo, nesta organização espacial, assim como no caleidoscópio, os sujeitos ou grupos estarão presentes, mesmo que entre eles exista uma maior ou menor visibilidade, inclusive componente importante nas estratégias da própria manutenção espacial de sua sobrevivência. Estas estratégias se renovam entre os indivíduos ou grupos e fazem com que o espaço público se reproduza e metamorfoseie continuamente.

Sobre este respeito, descreve Delgado:

El espacio publico es un espacio diferenciado, pero las técnicas prácticas y simbólicas que lo organizan, que le recuerdan, que lo someten a oposiciones, yuxtaposiciones, complementariedades, que los gradúan, que lo jerarquizan, etc., son poco menos que innumerables, proliferan hasta el infinito, son macroscópica, infinitesimales, y se renuevan a cada instante. (DELGADO RUIZ, p.3, 2002)

Esta complexa relação sócio-espacial, mediadas pelas esferas dos poderes em disputas pelo espaço e materializadas na forma do território entre os grupos são vivenciados de maneira peculiar, o que resulta em uma multiplicidade territorial no âmbito dos espaços públicos. Os limites e fronteiras que são estabelecidas no espaço público é resultado da ação destes grupos, dentre eles os marginalizados e as populações de ruas inseridas neste processo. Sua organização, justaposição, seletividade ou exclusividade será um resultado de um jogo de forças travadas nas inúmeras escalas do cotidiano.

Segundo esta questão:

El los espacios públicos, la territorialización viene dada sobre todo por lãs negociaciones que lãs personas establecen a propósito de cuál es su territorio y cuáles los limites de esse território. Esse espacio personal o informal acompaña a todo individuo allá donde va y se expande o contrae em función de los tipos de encuentro y em función de um buscado equilíbrio entre aproximación y evitación (DELGADO RUIZ, p2, 2002)

Contudo, os processos de produção espacial das populações de rua são definidos pelas impossibilidades formais e seu estabelecimento é duramente criticado por grande parte da sociedade. Assim, os espaços públicos para as populações de rua funcionam como o "local de sua territorialização, de sua casa. Ele escolhe lugares específicos para realizar seus desejos e "organizar" suas vidas"10 e o transformam em um lar, mesmo que também seja marcado pela precariedade, vulnerabilidade e instabilidades espaços-temporais.

Sobre os processos sócio-territoriais das populações de rua, descrevem Neves e Escorel: 
Por esta apropriação, incorporaram as praças e jardins, as calçadas dos centros comerciais ou de bairros mais dinâmicos em termos de circulação de pessoas, os espaços guardados por marquises, os viadutos, as casas abandonadas ou em ruínas, as cabines de telefone, os cruzamentos de avenidas de tráfico denso, os parques de estacionamento de carros, os entornos de supermercados e de shopping Center para trabalhar, pernoitar ou instalar suas residências (NEVES, p.125, 1999)

A escolha do local e sua qualificação em melhor ou pior são feitos levando em conta a segurança da localidade, o acesso à rede de sobrevivência (e sua opinião sobre ela) $e$ as relações estabelecidas com os transeuntes (ESCOREL, p.221, 1999)

Assim, os processos territoriais das populações de rua estão extremamente marcados pela dimensão da consciência, mesmo que se reconheça o nível de adversidades enfrentadas nos campos objetivos e materiais de sobrevivência física e simbólica. As populações de rua estão diante de muitas dificuldades e enfrentamentos. Além das dificuldades relacionadas a habitação, alimentação, vestimenta, saúde e segurança, estes grupos ainda possuem problemas internos dentro do próprio grupo, e principalmente com outros grupos sociais, devido as suas presenças e permanências espaciais nos espaços públicos.

As relações de poder que mediam a sociedade e consequentemente o espaço público, se organizam de maneira bastante hierarquizada, legitimando a permissão ou proibição de determinados grupos em praças, ruas, jardins, entre outros. Deste modo, em determinadas configurações, pode ser extremamente aceitável, a existência de grupos e/ou atividades comerciais, políticas ou culturais nos espaços públicos, mesmo que estes possuam fins privados. Entretanto, para as populações de rua, seus fins e especialmente por conta de sua relação assimétrica de inferioridade nas relações de poder, as restrições são reforçadas e dificuldades são ainda maiores nos processos de formações territoriais.

As mazelas que trazem no corpo, sejam nas roupas velhas, carrinhos de rolimãs ou de mercados, cachorros, sacos plástico, trouxas, garrafas e o aspecto de sujeira pela limitação de higienização em locais apropriados e públicos na maioria das metrópoles, acabam reforçando a legitimação de mais uma violência, a estigmatização social.

Assim, os processos de territorialização se constituem na permanência de instabilidades, onde as perseguições e riscos eminentes se tornam presentes e constituem de maneira flexível, ou melhor, respeitando "um processo de expansão e contração. Tais territórios têm a propriedade de ser 'elásticos', pois ora se expandem, ora se contraem, ocupando uma determinada porção do espaço público"11. 
Os territórios das populações de rua se configuram a partir das possibilidades, onde exista uma praça, um banco, uma marquise ou uma calçada de uma loja fechada temporariamente pode se tornar um espaço de proteção, aquisição de recursos e construção de laços afetivos e identitários. Assim, estes espaços ganham contorno e representação própria e se tornam parte integrante dos próprios sujeitos envolvidos neste processo.

Contudo, cabe refletir sobre as inúmeras forças que impedem as permanências destas realidades socioterritoriais. De maneira permanente, estas configurações territoriais são marcadas por des(re)territorializações nos espaços públicos. Grupos de comerciantes alegam que as populações de rua atrapalham o comércio local, por conta da ação de mendicância ou mesmo por conta do aspecto repulso e temeroso da miséria. Assim, desterritorializa-los, mesmo que temporariamente se faz uma ação importante, assim como uma questão de honra, tendo em vista, os discursos em torno "dos pagamentos dos impostos e a inação do Estado".

Com isto, as populações de rua sofrem inúmeras violências para que se desloquem, ou seja, se desterritorializem e levem consigo a sua condição de miséria. Lançamento de água no início das manhãs, espancamentos e até contratação de matadores de aluguel ${ }^{12}$ configuram esta realidade socioespacial contra os moradores de rua nos espaços públicos.

Em contrapartida, o Estado e suas ações de ordenamento territorial urbano, permanentemente buscam dar conta de uma "limpeza" urbana sobre os grupos marginalizados nos espaços públicos. Suas ações sociais para com as populações de rua são ineficazes e caminham muitas das vezes no campo do assistencialismo e das perpetuações das próprias condições. Criação de abrigos temporários, distribuição de alimentos e recolhimentos temporários legitimam de algum modo as suas presenças nos espaços públicos.

Pensar sobre estes processos de territorializações e territorialidades das populações de rua, seus enfrentamentos e dificuldades, fazem com que consideremos que estes espaços não sejam "percebidos apenas como uma posse ou como uma entidade exterior à sociedade que o habita"13. Assim, contrariando uma visão clássica de limites concretos e poderes institucionalizados formal e oficialmente que se enquadram os territórios, mas como uma condição dotada de múltiplas escalaridades e relações de poderes inerentes à própria condição humana.

Sua formação e os permanentes processos de (des)reterritorializações é um sinal claro dos movimentos de resistência destes grupos frente a todas as adversidades sofridas. Resistir neste sentido é negar a condição de inexistência é continuar minimamente humano em busca do que resta de sua humanidade.

\section{Considerações Finais}

De fato, faz-se necessário refletir processualmente sobre as territorializações e as territorialidades produzidas pelos grupos de moradores de rua nos espaços públicos das grandes metrópoles, pois "em graus diversos, em momentos diferentes e lugares variados, somos todos sintagmáticos que produzem "territórios"14. Por outras palavras, estas territorializações e 


\section{REVISTA TAMOIOS}

territorialidades tornam-se instrumentos identitários e concretos para a manutenção da vida, funcionando, como um conjunto de relações que mediam as possibilidades de sobrevivência, mesmo que de maneira precária, vulnerável ou flexível em relação às configurações espaços-temporais.

Neste sentido, os espaços públicos acabam por desempenhar um importante papel na vida destes sujeitos, mesmo que o Estado e outras forças atuem restringindo uma maior permanência destes, assim como reforçando a marginalização destes grupos nos últimos espaços possíveis.

Por certo, melhor do que refletirmos para além da compreensão das formas e as estratégias territoriais dos grupos marginalizados de um modo geral, é fundamental que caminhemos juntos na construção de novas formas possíveis de territorializarmos coletivamente para revertermos as forças que criaram justamente estes grupos sociais marginalizados. Deste modo, estamos certos que as populações de rua são um reflexo daqueles que lutam com todas as suas forças para continuarem as suas existências no espaço geográfico.

\section{Notas}

1- Graduado em Geografia pela Universidade Federal Fluminense e Mestre em História Social do Território pela Universidade do Estado do Rio de Janeiro. Atualmente é professor substituto na Universidade Federal Fluminense e na Universidade do Estado do Rio de Janeiro

2- Menção a obra de Henry Lefebvre, O direito à Cidade.

3- Destacamos em nossos referenciais: DELGADO RUIZ, GOMES, HABERMAS, NEVES, SENNETT e SERPA.

4- SENNETT, p.18

5- GOMES, p.160.

6- Ibidem, p.178

7- SENNETT, p. 28

8- GOMES, p.136.

9- Uma importante referência sobre este aspecto pode ser encontrado na obra do Geógrafo Rogério Haesbaert, intitulada: $O$ mito da desterritorialização: do "fim dos territórios" à multiterritorialidade.

10- LEITE, p.158.

11- MATTOS e RIBEIRO, p.26. Esta análise proposta por Ribeiro, sobre os grupos marginalizados, no caso específico das populações envolvidos na prostituição nas áreas centrais da cidade do Rio de Janeiro, revelam claramente como esta produção espacial se diferencia das demais formas, sobretudo, por serem grupos estigmatizados. Esta condição demarca 


\section{REVISTA TAMOIOS}

principalmente uma desproteção, por mais que estejam diante de uma "proteção" territorial.

12- No dia 23 de julho de 1993, na área central da cidade do Rio de Janeiro, oito moradores de rua, deis deste crianças foram brutalmente assasinados. Os assassinos eram policiais que teriam sido contratados para executarem a ação. Os executores foram julgados e presos, mas os mandantes continuam impunes.

13- HAESBAERT, p.72.

14- RAFFESTIN, p.152.

\section{Referências Bibliográficas}

DELGADO RUIZ, M. Etnografia Del espacio público. Revista Experimental de Antropologia, no2, Universidad de Jaen, 2002.

ESCOREL, S. Vidas Ao léu: trajetórias de exclusão social. Rio de Janeiro: Editora Fiocruz, 1999.

GOMES, P, C. A condição urbana: ensaios de geopolítica da cidade. Rio de Janeiro: Bertrand Brasil, 2006

HABERMAS, J. Mudança estrutural da esfera pública. Rio de Janeiro: Tempo Brasileiro, 1983.

HAESBAERT, R. O mito da desterritorialização: do "fim dos territórios" à multiterritorialidade. Rio de Janeiro: Bertrand Brasil, 2004.

LEITE, L. A razão dos Invencíveis. Meninos de rua: o rompimento da ordem (1554/1994). Rio de Janeiro: Editora UFRJ, 1998.

MATTA, R. A casa \& a rua: espaço, cidadania, mulher e morte no Brasil. Rio de Janeiro: Rocco, 1997.

MATTOS e RIBEIRO. Territórios da prostituição nos espaços públicos da área central do Rio de Janeiro. Revista Brasileira de Geografia. v.59, nำ1, Jan-Jun. Rio de Janeiro, 2005.

NEVES, D. Os miseráveis e a ocupação dos espaços públicos. Caderno $\mathrm{CRH}$, no31, Jan/Dez. Salvador, 1999.

PENHA, E, A. Território e territorialidades: considerações histórico-conceituais. Revista Brasileira de Geografia, v.59, no1, IBGE. 2005

RAFFESTIN, C. Por uma geografia do poder. São Paulo: Ática, 1993.

SCOTT, J. Los dominados y el arte de la resistencia: discursos ocultos. México, D.F: Ediciones Era, 2007.

SENNETT, R. O declínio do homem público. São Paulo: Cia das Letras, 1988.

SERPA, A. Espaço público e acessibilidade: notas para uma abordagem geográfica. Geousp - Espaço e Tempo, nº 15, São Paulo, 2004. 